\title{
An Analysis of Total Water Storage Changes Obtained from GRACE FO Observations over the Venezia Islands Area Supported with Additional Data
}

\begin{abstract}
The Venezia Islands are a very special area from the hydrological point of view due to its water mass changes. Regular floods results in the need for the regular monitoring of water mass changes. For this purpose, a Gravity Recovery and Climate Experiment mission (GRACE) can be used as a source of data.

The aim of the paper is to compare the latest results of the new GRACE FO observations. The comparisons were carried out all over Venezia Island using the L3 level, RL06 release data obtained with spherical harmonics degree and order extension of up to 120 , by the three most important computational centres: JPL, GFZ, CSR. Results are compared to an average month values of precipitation and evapotranspiration and tide gauge data in the nearby area.

Based on the research, no dependence between TWS and evapotranspiration and evapotranspiration change were found
\end{abstract}

Keywords: GRACE FO, total water storage, precipitation, evapotranspiration, tide gauges

Received: 24 August 2020; accepted: 2 February 2021

(C) 2021 Authors. This is an open access publication, which can be used, distributed and reproduced in any medium according to the Creative Commons CC-BY 4.0 License.

1 University of Warmia and Mazury in Olsztyn, Department of Geodesy and Civil Engineering, Olsztyn, Poland, email: monika.sienkiewicz@uwm.edu.pl

ORCID: https://orcid.org/0000-0002-8006-288X

2 University of Warmia and Mazury in Olsztyn, Department of Geodesy and Civil Engineering, Olsztyn, Poland, email: zofia.rzepecka@uwm.edu.pl ORCID ID: https://orcid.org/0000-0002-6570-9032 


\section{Introduction}

The research focuses on the analysis of the total water storage determined on the basis of the new GRACE FO (Gravity Recovery and Climate Experiment Follow-On) observation and comparing it with precipitation and evapotranspiration from the MERRA 2 model (The Second Modern-Era Retrospective analysis for Research and Applications), and then with tide gauge data. The research undertaken in the paper is to look for a possible relation between climatic parameters and TWS (total water storage). The research was carried out for the time span June 2018 - December 2019 for the area of the Venezia Islands. Different ways of processing were taken into consideration (traditional filtering and the newest mascon-solution). Having analysed and processed the values of monthly precipitation and evapotranspiration, an atmospheric budget was also estimated.

In the study TWS is analysed. Total water storage (TWS) is the sum of all water mass variations on land, atmosphere and in the soil; so, the sum of snow water equivalent, surface water, soil moisture and groundwater [1,2]. TWS was and is used in many applications, like computing TWS for big river basins, like e.g. the Amazon or Mekong [3], for the improvement of hydrological models [4], correct assimilation model outputs [5], computing water budget in combination with other products [6], estimating groundwater storage [1, 7], finding TWS relationship with climate variability and human activities [8].

Precipitation $(\mathrm{P})$ can be described as water droplets falling to the surface and can be in different forms: rain, sleet, snow and hail. It is usually measured as the rain volume which falls to the Earth per area unit per time unit. The rainfall rate can be used in many applications, such as water and energy cycle assessment, environmental and agricultural issues, weather forecasting, monitoring climate change, hydrological applications and natural disaster management $[9,10]$.

Evapotranspiration (EV) is the total value of evaporation and plant transpiration. It can be understood as water movement to the air from different sources on Earth (like soil, rivers, oceans, plants, etc.). In atmospheric models, the rate of evapotranspiration is presented as the volume of water lost from a surface unit per time unit. Evapotranspiration is used in applications such as water and atmospheric cycles evaluation, as well as weather and climate prediction models [11, 12].

The aim of the GRACE FO mission (Gravity Recovery and Climate Experiment Follow On) is to track the Earth's water movement in a global sense. It started on May 2018. GRACE satellites move on a quasi-polar orbit (89 inclination) at an altitude of about $500 \mathrm{~km}$. This allows for a global coverage of continental surfaces [2]. Observations consist of monitoring changes in the following: ice and glaciers, groundwater, the amount of water in basins, and changes in sea level. Such measurements provide a unique, precise, and global view of the Earth's climate. The on-ground GRACE Science Data System releases monthly solutions by three processing centres that use their own specific algorithm to obtain Level 2 data: 
GFZ, CSR and JPL. Data is provided on three levels, with the first level being raw data. The typical user usually analyses and process data on the second level, and in a somewhat different way for every centre [13].

For the purpose of obtaining the vales of monthly changes of precipitation and evapotranspiration data, MERRA 2 model outputs were obtained. The Modern-Era Retrospective analysis for Research and Applications (MERR2) is a NASA (National Aeronautics and Space Administration) atmospheric reanalysis model, determined for global, accurate spatial and time resolution releases of meteorological units. Outputs are based on satellite and terrestrial observations combined with GCM (General Circulation Model) simulations [14]. The data is available in grid form, at the $0.625^{\circ}$ longitude $\times 0.5^{\circ}$ latitude resolution [15] .

Tide gauges were obtained from a website of the Permanent Service for Mean Sea Level (PSMSL) [16], a service providing global data of mean sea level changes.

\section{Case Study - Venezia}

The study focuses on the Venezia Islands, one of the most interesting hydrological systems in southern Europe due to its island character and interesting hydrological situation. The analysed basin drains $60,500 \mathrm{~km}^{2}$. This study analyses water mass variations for both the land and sea area.

Venezia Islands are the biggest lagoon in the area of the Mediterranean (Figs. 1, 2).

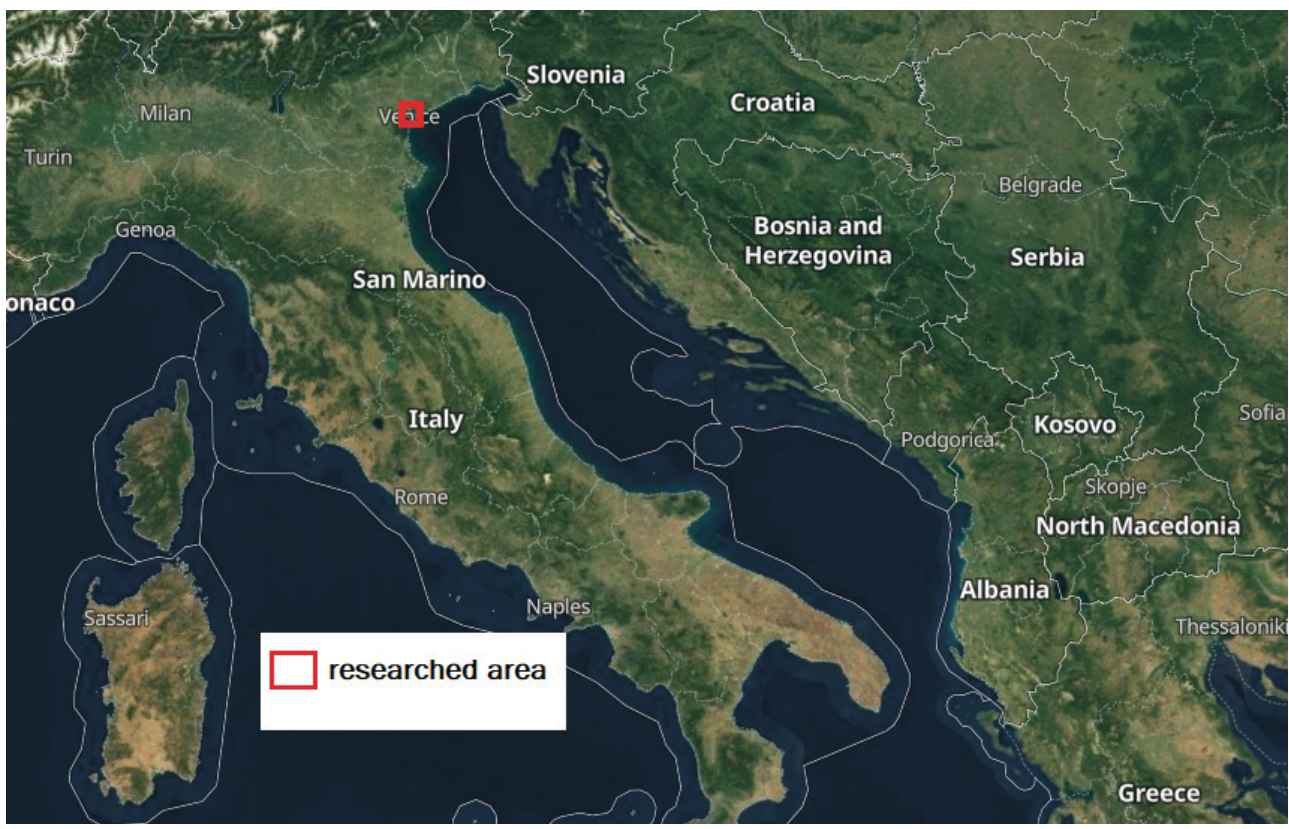

Fig. 1. Research location 


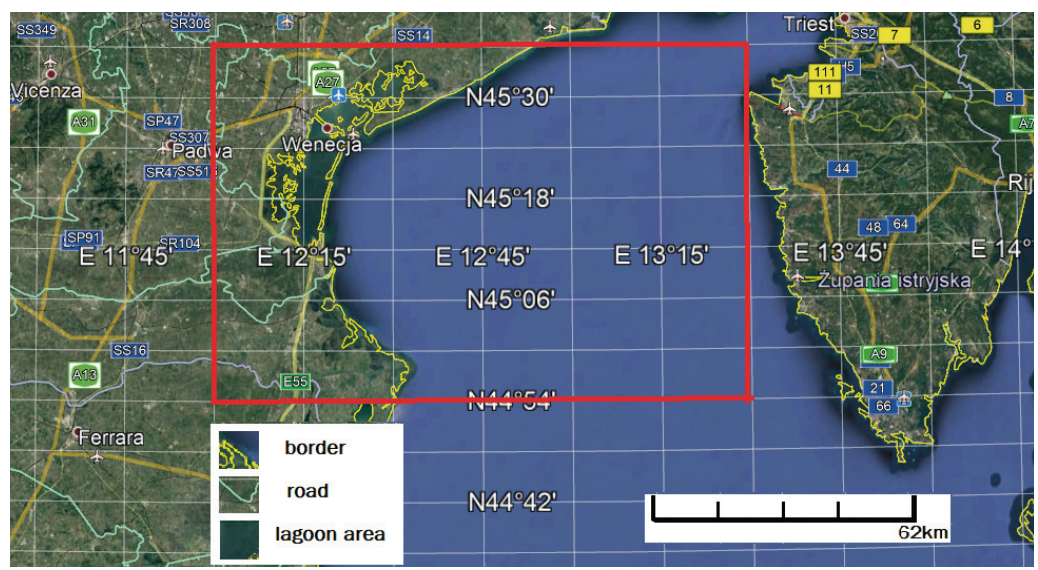

Fig. 2. GRACe grids used in the computation

The area can be characterized as a microtidal regime. According to the atmospheric conditions, especially the occurrence of the sirocco (strong winds from the south) and storms caused by a low atmospheric pressure should be emphasized. Such conditions influence the significant increase of the maximum water level [17-19].

\section{Methods}

In the paper a total water storage was determined and then compared to meteorological and tide gauge data. Thanks to the GRACE mission, we are able monitor processes that involve mass redistribution [20]. Because of this fact the total water storage changes from GRACE can then become a good basis for water and energetic budget analysis.

\subsection{Total Water Storage Determination Using Spherical Harmonics}

In the paper two ways of determining TWA are presented. The first is to compute TWS from the spherical harmonics coefficient extension with a degree and order of 120. As the raw data suffers from data leakage and needs a destriping process, Gauss filtering of a radius $300 \mathrm{~km}$ was introduced.

TWS was determined with the formula [21]:

$$
\Delta T W S=\frac{a \rho_{\text {ave }}}{\rho_{\text {water }}} \sum_{t=0}^{\infty} \sum_{m=0}^{l} \frac{2 l+1}{1+k_{l}} \overline{P_{l m}} \cos \theta\left(\Delta \overline{C_{l m}} \cos m \varphi+\overline{S_{l m}} \sin m \varphi\right),
$$

where: $\theta$ and $\varphi$ are colatitude and longitude, $a$ is the radius of the Earth equal $6378136.300 \mathrm{~m}, \rho_{\text {ave }}$ is the average density of the Earth equal $5517 \mathrm{~kg} / \mathrm{m}^{3}, \rho_{\text {water }}$ is the density of water equal $1000 \mathrm{~kg} / \mathrm{m}^{3}, k_{l}$ is the load Love number, and $P_{l m}$ is the fully normalized associated Legendre functions. 
To define the isotropic Gauss a radius $r$, and consists of the application of a weight, $W_{l m^{\prime}}$ added to the elements of the spherical harmonics coefficient $S_{l m}$ and $C_{l m}$. So, with a filtering weight, TWS changes estimated as [22, 23]:

$$
\Delta \text { TWS }=\frac{a \rho_{\text {ave }}}{\rho_{\text {water }}} \sum_{t=0}^{\infty} \sum_{m=0}^{l} \frac{2 l+1}{1+k_{l}} W_{l m} \overline{P_{l m}} \cos \theta\left(\Delta \overline{C_{l m}} \cos m \varphi+\overline{S_{l m}} \sin m \varphi\right) .
$$

The radius $r$ of the Gauss filter only defines the filter approximately, its purpose is to fix the spatial resolution of the filtered grids.

\subsection{Total Water Storage Determination Using Mascons}

On the other hand, mascon processing of GRACE observations was used. Mascons (mass concentrations blocks) are some kind of mass concentration beneath the surface of a planet and are the cause of changes in the gravitational field. Mascon parameters are used to obtain geographical corrections for the mean global gravity field. Each of the parameters represents the excess or deficit of surface mass for a specific area and a designated time period. The excess or deficit of surface mass determined for a specific area is represented as a uniform layer of mass, which is expressed in meters of total water storage in that region. In other words, mascons represent the distribution of surface mass as spatial and temporal functions [24].

\subsection{Steps of Research}

All in all, based on GRACE observations, TWS variations are computed using two techniques (Fig. 3).

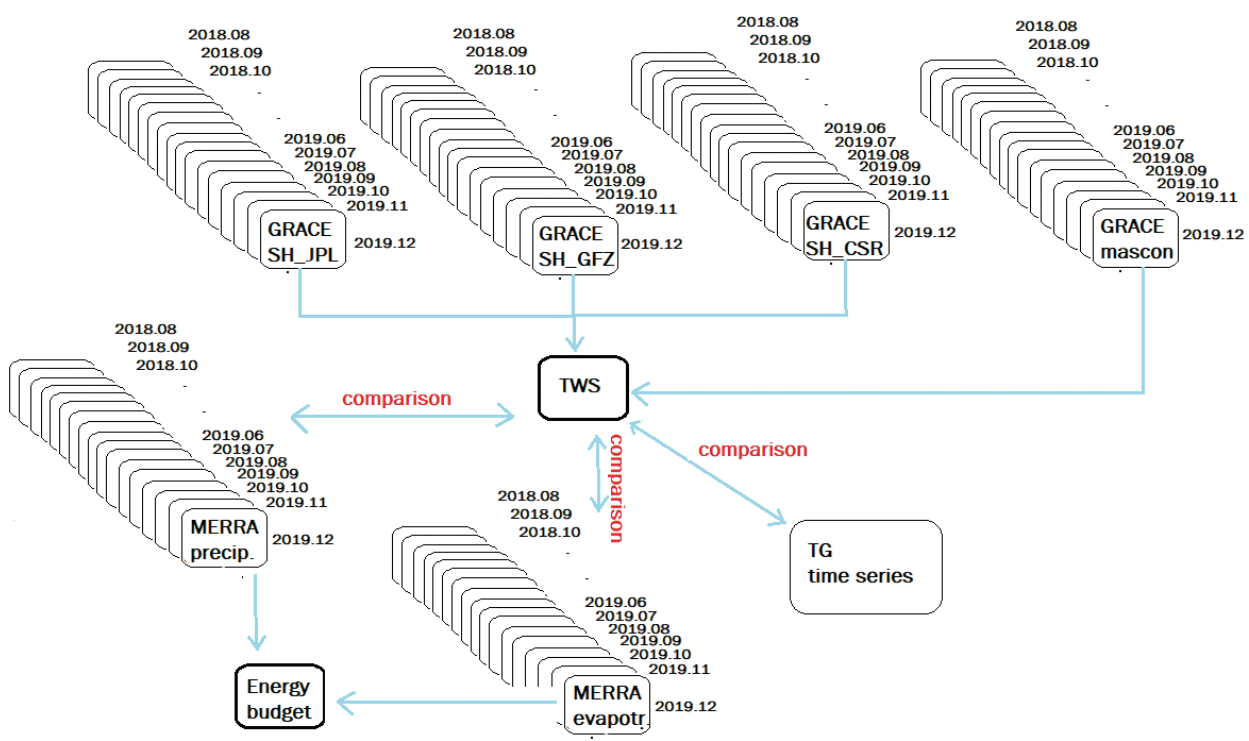

Fig. 3. Flowchart of GRACE observations processing 
Next, TWS changes are analysed in terms of looking for the causes of changes. Precipitation and evapotranspiration from the satellite model, and sea level changes due to tide gauges will be taken into account. Due to the marine climatic zone, the relatively flat surface (a small part of the researched area is land, which can be classified as flat), canopy and surface topography influence will not be considered.

\section{Results and Discussion}

From a website [25] the observations concerning total water storage were downloaded. Three types of postprocessing were taken into calculation - Release Note 06 computed in the computation centres JPL - Jet Propulsion Laboratory [26] GFZ - German Research Centre for Geosciences (GeoForschungsZentrum) [27] and CSR - Center for Space Research at University of Texas, Austin [28]. Gridded surface TWS variations over the Venezia Island area were derived from spherical harmonic coefficients that represent the Earth's mean gravity field estimations during the specified one-month timespan. Obtained results are a good approximation of the full magnitude of land hydrology and land ice. For the purpose of raw data filtering, a Gauss filter with a $300 \mathrm{~km}$ radius was used [29].

GRACE data with a spatial resolution of approximately $100 \mathrm{~km}$ is characterized with a significant noise ratio (the noise increases with degrees of the spherical harmonic decomposition striving for a higher spatial resolution). The aim of the three mentioned centres is to reduce noise by applying smoothing filters. In fact, smoothing filters cause the smoothing of the amplitude of the water mass variations. Moreover, TWS also suffers leakage effects [3, 30]. D. Long et al. [31] made research on 60 river basins and noticed more disparities in TWS trend for medium basins that are less than $200,000 \mathrm{~km}^{2}$. Based on the research it can be said that more differences in TWS are more likely to be noticed for medium and small watersheds. The research area covers a small zone, so three solutions were considered (Fig. 4).

Correlation coefficients were computed between all the time series, the results are as follows:

- GFZ/JPL: 0.972,

- GFZ/CSR: 0.975,

- JPL/CSR: 0.983.

Analysing the values of TWS over the Venezia Islands led the authors to notice that the smallest values of TWS change were achieved in late-autumn period $(-13 \mathrm{~cm}$ in October 2018 and $-15 \mathrm{~cm}$ in October 2019). In summer, the TWS change is almost zero (0.6 cm in June 2019). Analysing old TWS data measured by the GRACE mission from 2002 to 2017 let us notice that such a tendency is stable over the years, with values of about $14 \mathrm{~cm}$ in autumn and about $0 \mathrm{~cm}$ in the beginning of the summer [32]. 


\section{total water storage_GRACE FO}
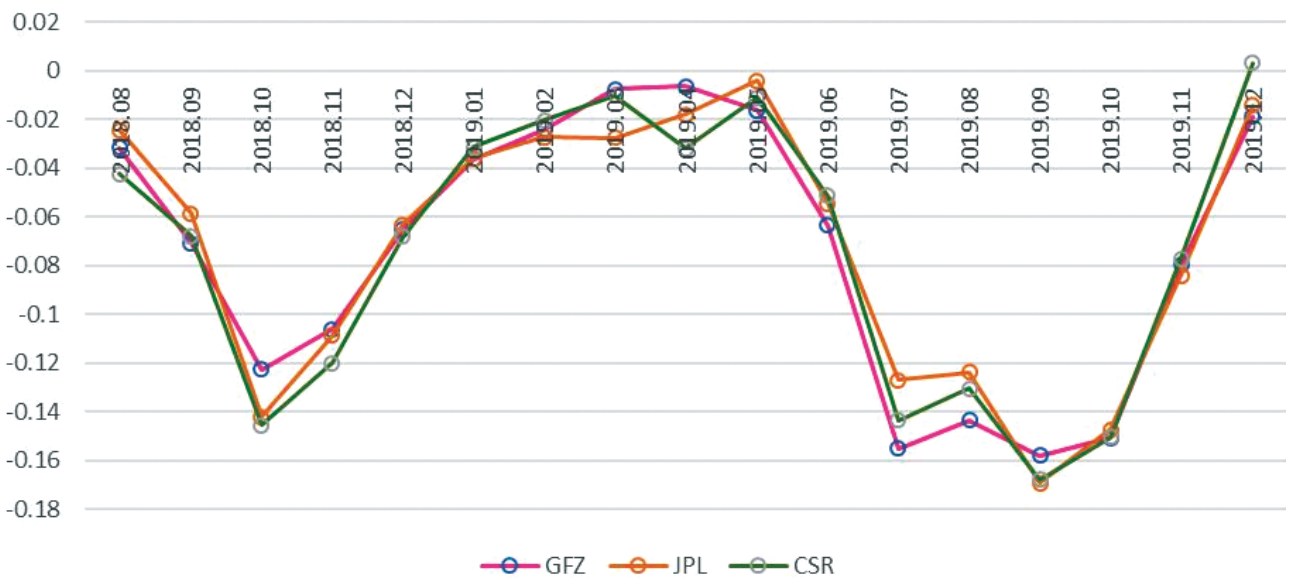

Fig. 4. Total water storage changes - time series for GFZ, JPL and CSR solution filtered with Gauss, $300 \mathrm{~km}$ radius, for the whole researched area of the Venezia Islands, unit: metres

According to [13], it is recommended to use a simple arithmetic mean of the JPL, CSR, GFZ fields. Such an approach seems to be the most effective in cases of reducing the noise in the solutions. The differences between solutions of JPL, GFZ, and CSR releases are rather small, and are dependent on the error bounds of the GRACE solution itself [13]. Because the correlation coefficient is more than 0.9 , time series filtered with Gauss $300 \mathrm{~km}$ were averaged. In the next step of the research, it was checked if the averaged filtered solutions correspond to the newest mascons solutions.

In comparison to the filtering solution, the aim of mascons is to parameterize the Earth's gravity field with mass concentration functions. Such a solution causes the decrease of leakage [33]. In the paper, the mascon solution computed by the JPL centre $\left(0.5^{\circ} \times 0.5^{\circ}\right.$ grid, RL06 M.MSCNv01 dataset with Coastal Resolution Improvement Filtering [34]) was used (Fig. 5).

The correlation coefficient between the mascon solution and the average time series of filtered TWS values is very high (0.995). It can be said that for the area of the Venezia Islands, both solutions can be used interchangeably.

Using the web-service [35], two sets of MERRA 2 outputs were obtained in a one-month time resolution: precipitation and evapotranspiration. The data was averaged for every month over the researched area. Analysing the evapotranspiration time series, a smooth regular line is noticed. The Venezia Islands have a moderately warm climate, and annual amplitudes of the temperature are rather small. Figure 6 reflects the climate. In summer, when more sun radiation and longer days are noted, values of evapotranspiration are on the level from 3.5 to $5 \mathrm{e}-5 \mathrm{~kg} / \mathrm{m}^{2} / \mathrm{s}$. In winter months, evapotranspiration is about $1.5 \mathrm{e}-5 \mathrm{~kg} / \mathrm{m}^{2} / \mathrm{s}$. Precipitation rate over year is 
more irregular, during the analysed period the highest value is noticed in November $2019\left(10 \mathrm{e}-5 \mathrm{~kg} / \mathrm{m}^{2} / \mathrm{s}\right)$. It needs to be mentioned that this was the time of a very dangerous flood that occurred in Venezia Lagoon (caused by an unexpectedly huge tide) while a year before, in November 2018, the value of precipitation was only $4.2 \mathrm{e}-5 \mathrm{~kg} / \mathrm{m}^{2} / \mathrm{s}$.

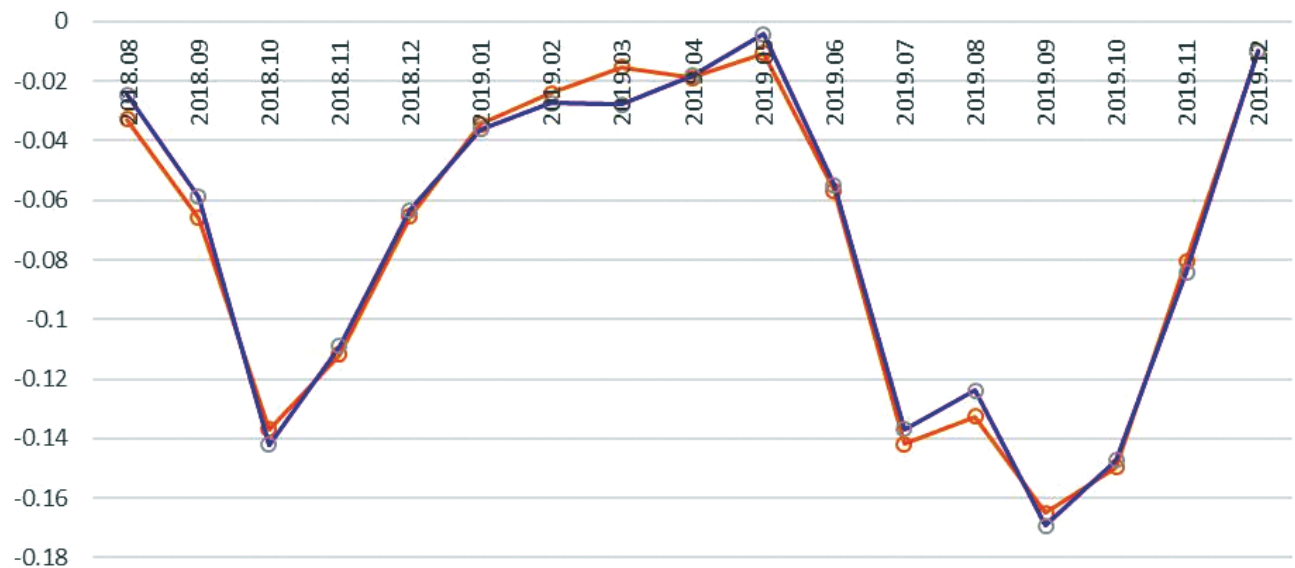

$$
\multimap \text { av. GRACE FO filt. } \quad \text { - } \quad \text { GRACE FO masc. }
$$

Fig. 5. Total water storage changes - time series for averaged GFZ, JPL and CSR solution filtered with Gauss, $300 \mathrm{~km}$ radius, and time series for mascon solution, for the whole researched area of the Venezia Islands, unit: metres

\section{precipitation/evapotranspiration}

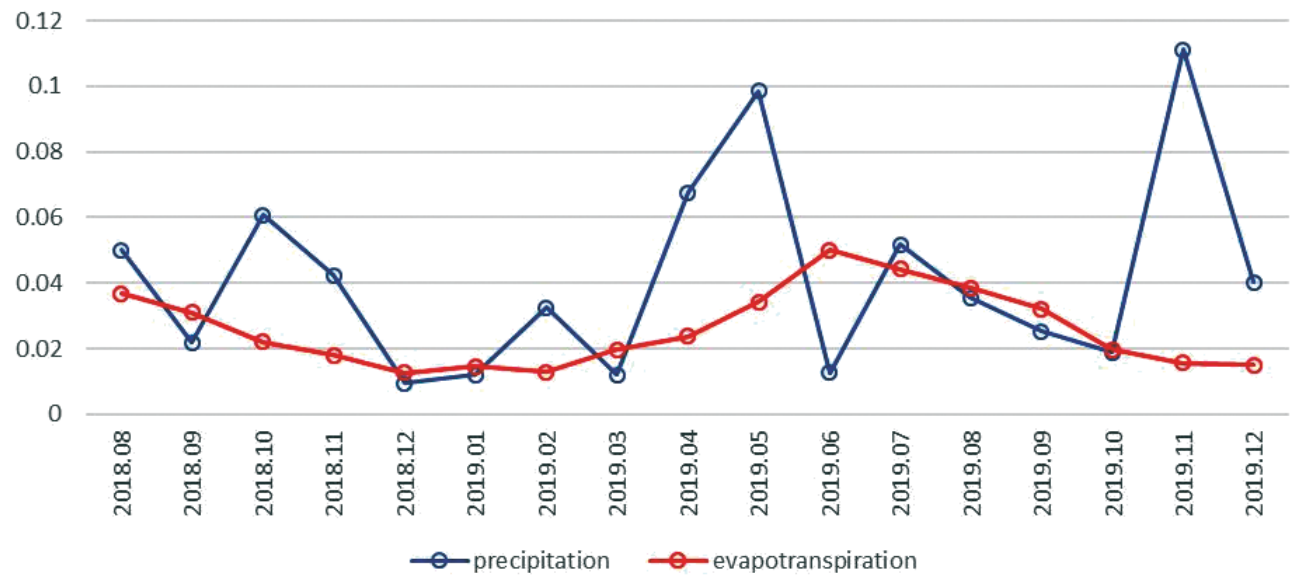

Fig. 6. Precipitation and evapotranspiration outputs from the MERRA 2 model, for the entire research area of the Venezia Islands, unit: $\mathrm{kg} / \mathrm{m}^{2} / \mathrm{s}$ 
The values of precipitation and evapotranspiration were recomputed into metres for the purpose of performing a comparison between the TWS and MERRA 2 outputs (Fig. 7). It can be said that there is no relation between evapotranspiration and TWS as the value and amplitude of an evapotranspiration change is insignificantly small in comparison with TWS. Analysing the relation between precipitation change and TWS change, much higher values are noticed according to precipitation. The precipitation rate seems to have very little influence on TWS variations. As Venezia is characterized with an island geographical location, it seems that tides have such a huge influence that determines most of the monthly TWS values. No significant linear relationship has also been demonstrated in Figures 8 and 9, where a scatterplot of correlation between TWS and precipitation, together with TWS and evapotranspiration, are presented.

total water storage_GRACE FO/precipitation/evapotranspiration

\subsection{5}

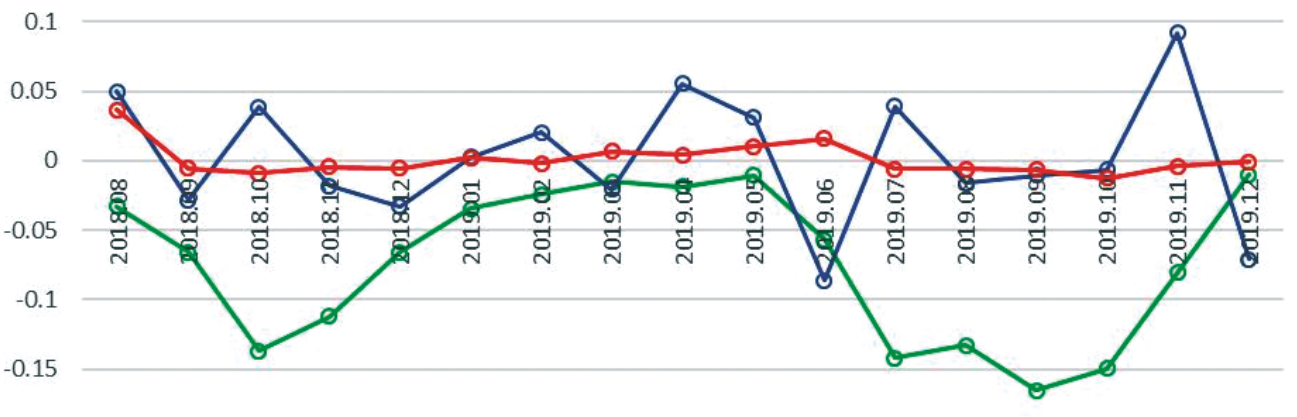

$$
\text { -av. TWS } \rightarrow \text { precipitation }- \text { evapotranspiration }
$$

Fig. 7. Comparison between average total water storage changes, precipitation and evapotranspiration, for the whole researched area of the Venezia Islands, unit: metres

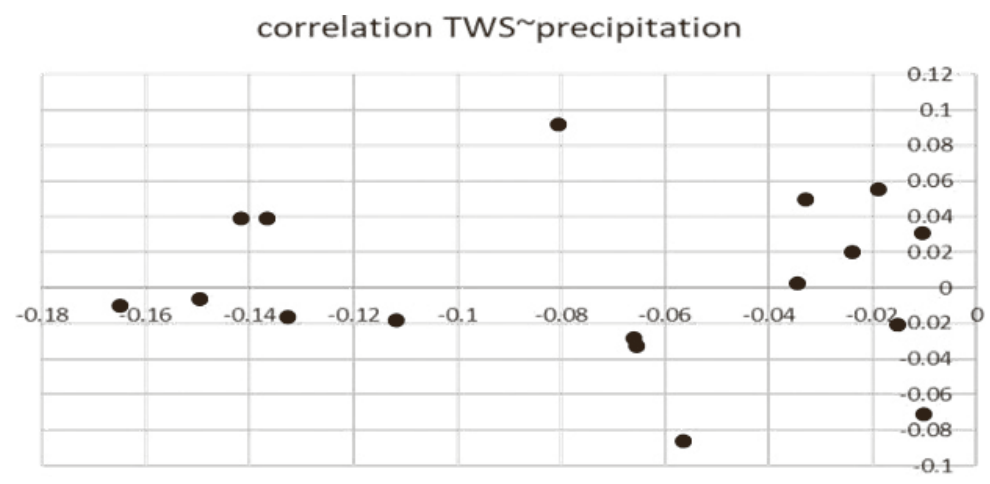

Fig. 8. Relation between TWS and precipitation, for the area of the Venezia Islands, unit: metres 


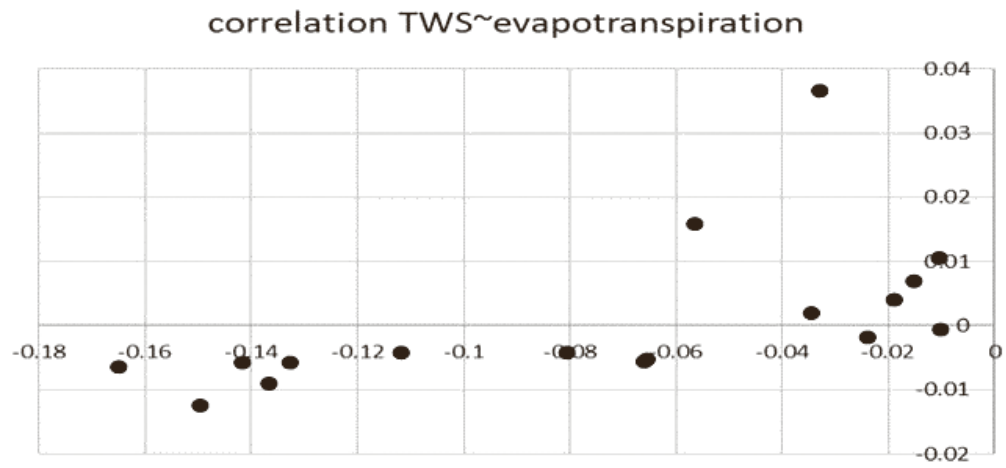

Fig. 9. Relation between TWS and evapotranspiration, for the area of the Venezia Islands, unit: metres

In the near surroundings of Venezia, four mareograph stations are to be found:

- VENEZIA ARSENALE (45.417; 12.350),

- VENEZIA II $(45.418 ; 12.427)$,

- VENEZIA - S.STEFANO (45.417; 12.333),

- VENEZIA - PUNTA DELLA SALUTE (45.433; 12.333).

For the purpose of the research of tide gauge changes, a mareograph from VENEZIA II was taken, having the most up to date data. The comparison between TWS and mean sea level changes is presented in Figure 10.

\section{atmospheric budget}

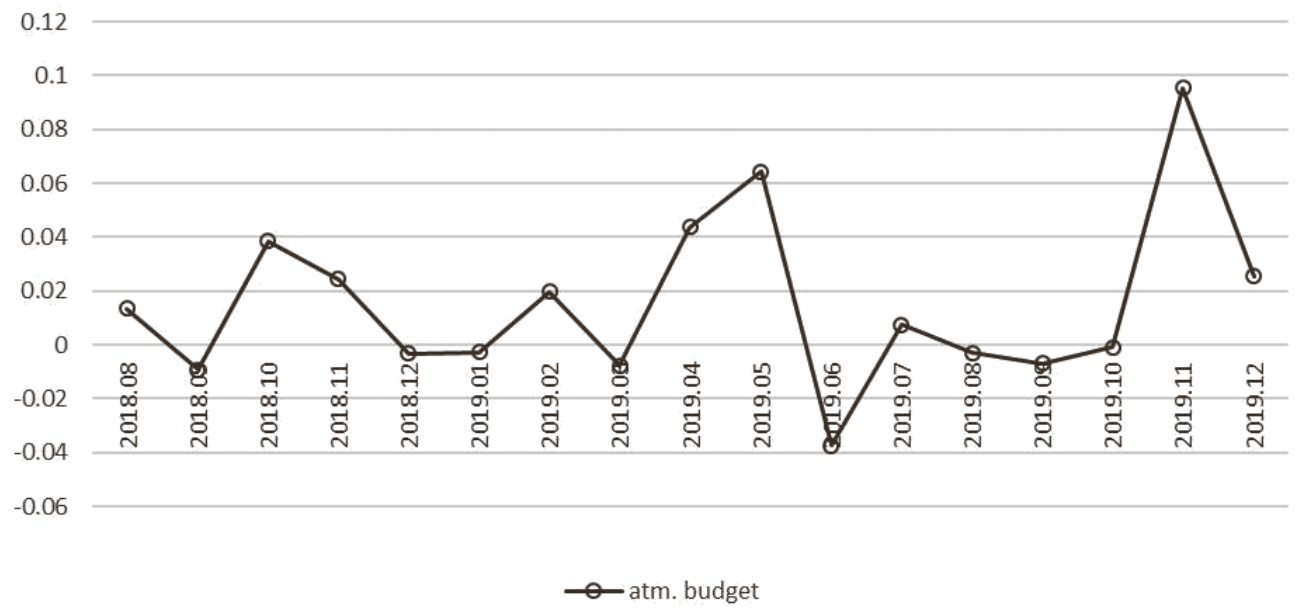

Fig. 10. Relation between TWS and tide gauges changes, for the whole researched area of the Venezia Islands, unit: metres 
This can prove that any change of mean sea level change is quickly reflected in TWS changes. Values from tide gauge measurements are higher that TWS changes, bringing the conclusion that some big run off is expected in a region up to about 0.25 metres change) yet it can be noticed that phases of changes are the same. A rise of both TWS and tide gauge data change was observed for the period December 2018 - June 2019, then during a period July 2019 - November 2019 negative values are observed. It would be interesting to extend the time series of measurement for the purpose of looking for seasonal repeat.

The last part of the research was to compute the availability of fresh water in the area. Having the values of precipitation and evapotranspiration, an atmospheric budget over the region was also computed (Fig. 11). Freshwater availability monitoring and understanding is of immense importance, especially in assessing the social, economic, and environmental impacts of climate change. Estimation of the approximate freshwater availability can be computed as the difference (P-E) between precipitation $(\mathrm{P})$ and evapotranspiration (E). Such an approach is widely practiced because of its simplicity [36-38].

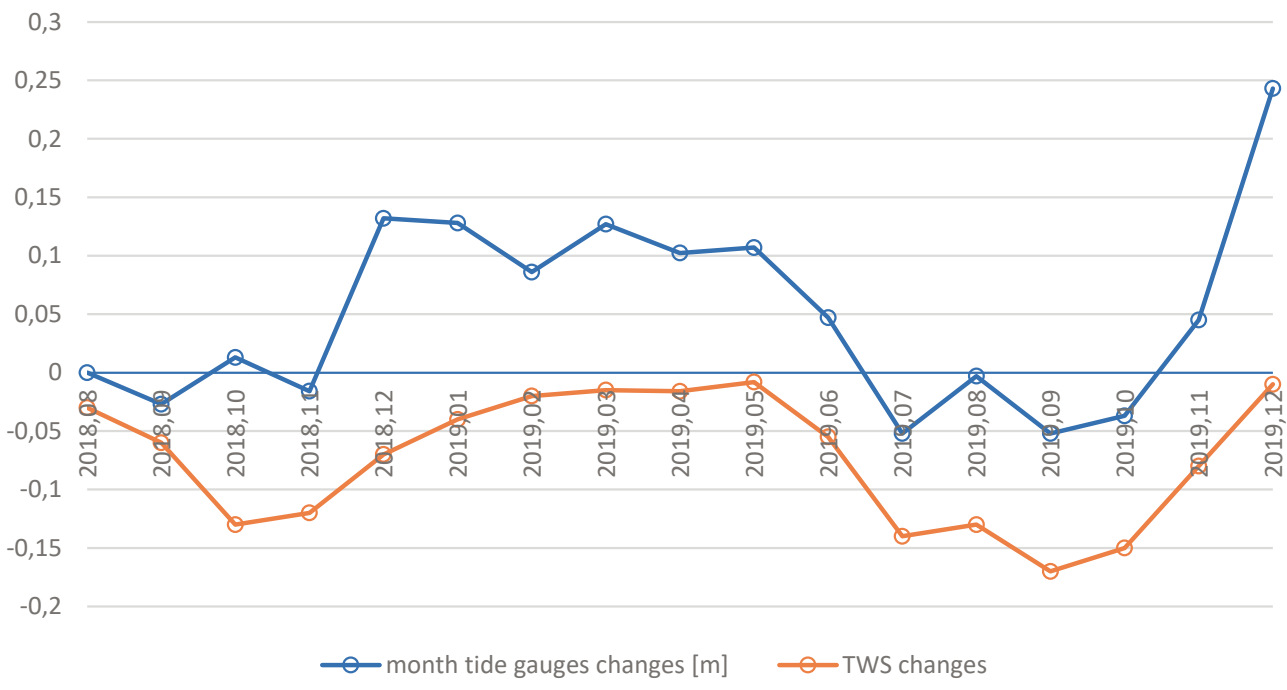

Fig. 11. Atmospheric budget for the area of the Venezia Islands, unit: metres

In the area of the Venezia Islands, an atmospheric budget in half of the researched months gained a so-called normal value (approx. 0). This means that precipitation and evapotranspiration chance is balanced. The only below normal value was noticed in June $2019(-4 \mathrm{~cm})$. The highest values of the atmospheric budget, an above normal budget, were noticed in November $2019(9 \mathrm{~cm})$, May $2019(6.5 \mathrm{~cm})$ and in October $2018(4 \mathrm{~cm})$. 


\section{Conclusions}

The aim of the paper was to check for dependencies between total water storage change and precipitation and evapotranspiration change over the area of the Venezia Islands. Based on the research, a few conclusions were drawn.

1. No dependence between TWS and evapotranspiration and evapotranspiration change was found. The major impact on TWS change must be by the influence of tides.

2. There is a high correlation between all analysed filtered solutions (GFZ, JPL and CSR) and between averaged filtered solution and the newest mascon solution over the Venezia Islands. Both solutions can be used interchangeably.

3. A similar phase of changes can be observed when comparing TWS changes and tide gauge data changes.

4. Atmospheric budget analyses reveal normal or above normal values which is a good prognostic of the availability of fresh water.

\section{References}

[1] Chen J., Famiglietti J.S., Scanlon B.R., Rodell M.: Groundwater storage changes: present status from GRACE observations. Surveys in Geophysics, vol. 37(2), 2016, pp. 397-417.

[2] Biancamaria S., Mballo M., Le Moigne P., Pérez S.J.M., Espitalier-Noël G., Grusson Y., Cakir R., Häfliger V., Barathieu F., Trasmonte M., Boone A., Martin E., Sauvage S.: Total water storage variability from GRACE mission and hydrological models for a 50,000 $\mathrm{km}^{2}$ temperate watershed: the Garonne River basin (France). Journal of Hydrology: Regional Studies, vol. 24, 2019, 100609.

[3] Wouters B., Bonin J.A., Chambers D.P., Riva R.E.M., Sasgen I., Wahr J.: GRACE, time-varying gravity, Earth system dynamics and climate change. Reports on Progress in Physics, vol. 77, no. 11, 2014, 116801.

[4] Niu G.Y., Yang Z.L.: Assessing a land surface model's improvements with GRACE estimates. Geophysical Research Letters, vol. 3, 2006, L07401.

[5] Zaitchik B.F., Rodell M., Reichle R.H.: Assimilation of GRACE terrestrial water storage data into a land surface model: results for the Mississippi River basin. Journal of Hydrometeorology, vol. 9(3), 2008, pp. 535-548.

[6] Gao Y., Tang Q., Ferguson C.R., Wood E.F., Lettenmaier D.P.: Estimating the water budget of major US river basins via remote sensing. International Journal of Remote Sensing, vol. 31, no. 14, 2010, pp. 3955-3978.

[7] Śliwińska J., Birylo M., Rzpecka Z., Nastula J.: Analysis of groundwater and total water storage changes in Poland using GRACE observations, in-situ data, and various assimilation and climate models. Remote Sensing, vol. 11, 2019, 2949. 
[8] Rodell M., Famiglietti J.S., Wiese D.N., Reager J.T., Beaudoing H.K., Landerer F.W., Lo M.H.: Emerging trends in global freshwater availability. Nature, vol. 557, 2008, pp. 651-659.

[9] Saha G.C.: Climate Change Induced Precipitation Effects on Water Resources in the Peace Region of British Columbia, Canada. Climate, vol. 3(2), 2015, pp. 264-282.

[10] GES DISC: Giovanni Measurement Definitions: Precipitation. https://disc.gsfc. nasa.gov/information/glossary?keywords=giovanni\%20measurements\&title=Giovanni\%20Measurement\%20Definitions:\%20Precipitation [access: 10.02.2020].

[11] Moorhead J.E., Marek G.W., Gowda P.H., Lin X., Colaizzi P.D., Evet S.R., Kutikoff S.: Evaluation of Evapotranspiration from Eddy Covariance Using Large Weighing Lysimeters. Agronomy, vol. 9, no. 2, 2019, 99.

[12] LDAS - Land Data Assimilation System. http://ldas.gsfc.nasa.gov/faq/\#NLDAS_evap [10.02.2020].

[13] Sakumura C., Bettadpur S., Bruinsma S.: Ensemble prediction and intercomparison analysis of GRACE time-variable gravity field models. Geophysical Research Letters, vol. 41(5), 2014, pp. 1389-1397.

[14] Wargan K., Labow G., Frith S., Pawson S., Livesey N., Partyka G.: Evaluation of the Ozone Fields in NASA's MERRA-2 Reanalysis. Journal of Climate, vol. 30(8), 2017, pp. 2961-2988.

[15] Rienecker M.M., Suarez M.J., Gelaro R., Todling R., Bacmeister J., Liu E., Bosilovich M.G., Schubert S.D., Takacs L., Kim G.K., Bloom S., Chen J., Collins D., Conaty A., da Silva A., Gu W., Joiner J., Koster R.D., Lucchesi R., Molod A., Owens T., Pawson S., Pegion P., Redder C.R., Reichle R., Robertson F.R., Ruddick A.G., Sienkiewicz M., Woollen J.: MERRA: NASA's Modern-Era Retrospective Analysis for Research and Applications. Journal of Climate, vol. 24(14), 2011, pp. 3624-3648.

[16] PSMSL - Permanent Service for Mean Sea Level. https://www.psmsl.org/ [access: 18.02.2020].

[17] Molinaroli M., Guerzoni S., Sarretta A., Cucco A., Umgiesser G.: Links between hydrology and sedimentology in the Lagoon of Venice, Italy. Journal of Marine Systems, vol. 68(3-4), 2007, pp. 303-317.

[18] Pirazzoli P.A.: Possible defences against a sea level rise in the Venice area, Italy. Journal of Coastal Research, vol. 7, no. 1, 1991, pp. 231-248.

[19] Canestrelli P., Mandich M., Pirazzoli P.A., Tomasin A.: Wind, depression and seiches: tidal perturbations in Venice (1951-2000). Technical Report, Comune di Venezia, Centro Previsioni e Segnalazioni Maree, Venice, Italy, 2001.

[20] Wahr J., Molenaar M., Bryan F.: Time variability of the Earth gravity firld: hydrological aand oceanic effects and their possible detection using GRACE. Journal of Geophysical Research - Solid Earth, vol. 103(B12), 1998, pp. 30205-30229. 
[21] Hassan A., Jin S.: Water cycle and climate signals in Africa observed by satellite gravimetry. IOP Conference Series: Earth and Environmental Science, vol. 17, 2014, 012149.

[22] Jekeli C.: Alternative Methods to Smooth the Earth's Gravity Field. Geodetic and Geoinformation Science Department of Civil and Environmental Engineering and Geodetic Science, The Ohio State University, Columbus, Ohio 1981.

[23] Swenson S., Wahr J.: Methods for inferring regional surface mass anomalies from Gravity Recovery and Climate Experiment (GRACE) measurements of time-variable gravity. Journal of Geophysical Research - Solid Earth, vol. 107(B9), 2002, pp. ETG 3-1-ETG 3-13.

[24] Rowlands D., Luthcke S., McCarthy J., Klosko S., Chinn D., Lemoine F., Boy J.-P., Sabaka T.: Global mass flux solutions from GRACE: A comparison of parameter estimation strategies - Mass concentrations versus stokes coefficients. Journal of Geophysical Research - Solid Earth, vol. 115(B1), 2010, B01403.

[25] GRACE-FO - NASA. https://gracefo.jpl.nasa.gov/ [access: 3.02.2020].

[26] JPL GRACE Tellus - NASA. https://grace.jpl.nasa.gov/ [access: 8.02.2020].

[27] GRACE-FO Geopotential GSM Coefficients GFZ RL06. http://dataservices.gfz-potsdam.de/gracefo/showshort.php?id=escidoc:4289898 [access: 8.02.2020].

[28] PO.DAAC - NASA. https://podaac.jpl.nasa.gov/ [access: 8.02.2020].

[29] Swenson S., Wahr J.: Post-processing removal of correlated errors in GRACE data. Geophysical Research Letters, vol. 33(8), 2006, L08402.

[30] Longuevergne L., Scanlon B.R., Wilson C.R.: GRACE Hydrological estimates for small basins: Evaluating processing approaches on the High Plains Aquifer, USA. Water Resources Research, vol. 46(11), 2010, W11517.

[31] Long D., Pan Y., Zhou J., Chen Y., Hou X., Hong Y., Scanlon B.R., Longuevergne L.: Global analysis of spatiotemporal variability in merged total water storage changes using multiple GRACE products and global hydrological models. Remote Sensing of Environment, vol. 192, 2017, pp. 198-216.

[32] The GRACE Plotter. http://thegraceplotter.com/ [access: 21.02.2020].

[33] Scanlon B.R., Zhang Z., Save H., Wiese D.N., Landerer F.W., Long D., Longuevergne L., Chen J.: Global evaluation of new GRACE mascon products for hydrologic applications. Water Resourches Research, vol. 52(12), 2016, pp. 9412-9429.

[34] Watkins M.M., Wiese D.N., Yuan D.N., Boening C., Landerer F.W.: Improved methods for observing Earth's time variable mass distribution with GRACE using spherical cap mascons. JGR Solid Earth, vol. 120(4), 2015, pp. 2648-2671.

[35] NASA Giovanni. https://giovanni.gsfc.nasa.gov/giovanni/ [access: 31.01.2020]. 
[36] Trenberth K.E., Fasullo J.T.: North American water and energy cycles. Geophysical Research Letters, vol. 40, 2016, pp. 365-369.

[37] Oki T., Kanae S.: Global hydrological cycles and world water resources. Science, vol. 313, 2006, pp. 1068-1072.

[38] Parish E.S., Kodra E., Steinhaeuser K., Ganguly A.R.: Estimating future global per capita water availability based on changes in climate and population. Computers \& Geosciences, vol. 42, 2012, pp. 79-86. 